\title{
The Hierarchical Structure of Chinese Higher Education System*
}

\author{
Han Meng-jie, Guo Chi \\ Dalian University of Technology, Dalian, China
}

\begin{abstract}
Higher education system can be divided into the dichotomy of structure according to mission and reputation of the institutes: equipollent or hierarchical. However, the hierarchical structure is in conflict with the value of social justice; the equipollent structure is just the pursuit of equal access to higher education. It is a fundamental issue of public policy how to balance the positive and negative aspects of higher education structure, which involves choosing the value of equity, competence, and liberty. Therefore, the government should motivate institutes to stick to their goals to enhance reputation in their respective types, avoid the hierarchical structure of higher education, and especially enhance the mobility of different levels and types of institutes.
\end{abstract}

Keywords: higher education system, hierarchical structure, social justice, China

\section{Introduction}

The higher education system is usually a complicated academic system, and its components are correlative and interactional. At the national level, higher education institutes are just like a net structure. From the horizontal point of view, the structure of higher education system is composed by different types of institutes; from the longitudinal point of view, the structure is composed by hierarchical reputation of institutes. The structure of higher education system is influenced by its political system, financial conditions, and historical and cultural tradition. However, the national systems of higher education always vary substantially according to the extent of diversity and the role dimension of diversity play (Kim \& Lee, 2006). Even though many national higher education systems have been fully analyzed, Chinese higher education system is seldom mentioned in the Western world. Therefore, we take China as an example to examine the structural changes of Chinese higher education system in its political economical environments (Han \& Zhang, 2014a).

\section{Theoretical Framework: Higher Education System and Its Structure}

Teichler (2006) identified the formal dimensions of diversity to characterize the structure of higher education system: (a) types of institutions and programs (e.g., universities $v s$. Fachhochschulen); and (b) levels of programs and degrees (e.g., bachelor, master, and doctoral programs). Also, he disentangled: (a) vertical attributes of informal diversity, such as "quality," "excellence," "elite," or "reputation"; and (b) horizontal attributes, such as "profile" of a higher education institution. Most debates on the formal and informal diversity refer explicitly to higher education institutions as key carriers of homogeneity and diversity. Besides, other

\footnotetext{
* Acknowledgments: The study is funded by the National Education Scientific Planning Project (CIA140190), the Ministry of Education's Major Project of Philosophy and Social Science (14JZD051), and the National Universities' Basic Scientific Research Project [DUT14RC(3)069].

Han Meng-jie, Ph.D., lecturer, Institute of Higher Education, Dalian University of Technology.

Guo Chi, Ph.D. candidate, associate professor, deputy dean, Graduate School, Dalian University of Technology.
} 
scholars research on regional structure of higher education in the context of the unbalanced development across China's provinces (Han \& Song, 2014).

As we all know, there are three main missions of higher education, i.e., to cultivate talents, to do scientific research, and to serve the society. The activities of higher education are more or less carried out in different institutes. Academic systems, in varying degrees, have their activities separated into different types of institutions. These institutions, deliberately or otherwise, are arranged in hierarchies. Along with the increase of activities, the ordinal scale of institutes becomes more obvious and important. It is the hierarchical structure not the internal structure that largely determines the nature and functions of the academic system.

The vertical arrangements of institutions and sectors are of two sorts: high and low placement based on prestige, a hierarchy of sequence; and ranking based on prestige, a hierarchy of status, which is often but not always closely related to the first (Clark, 1983). One is from higher education institutions based on mission scope. According to the location in the hierarchy of higher education system, we predict that activities carried out in different institutes vary. The research-based institutes may be on the top, general education may be in lower level, while special education lies in higher level. The other kind of hierarchy of higher education system is based on reputation. Different institutes enjoy a different reputation. Different graduate outcomes also result in different reputation. The division by mission is more objective without subjective influence. Even though institutes enjoy the same reputation level, their mission levels probably vary. However, division by reputation relates to more subjective value judgment. If there is less liquidity between different levels of institutes' mission, the hierarchy based on reputation will be more explicit and stiff. The hierarchy usually means the reputation hierarchy based on recognized graduate social value.

In different countries, characteristics of academic system hierarchy are different. In brief, there are three types of academic hierarchy. In the first type, several institutions have a monopoly, or near-monopoly, of elite placement that helps to give them much higher prestige than all others. Japan is an outstanding example. A small set of imperial governmental institutions experienced rapid modernization in the late 19th and early 20th centuries. Within the cluster of seven institutions, the universities of Tokyo and Kyoto were given, and seized, an even more special place. They became a class unto themselves, to the point where certain high positions in government could be entered only by graduation from certain faculties. A high degree of institutional hierarchy has been found also in French and Great Britain. In these countries, several institutes monopolize the apex of academic system hierarchy. The advantageous status can obtain much more reputation for these institutes than other institutes. The middle ground of status hierarchy is occupied by such systems as the Canadian and the American, in which pronounced differences exist in the social standing of institutions and sectors, without a few institutions monopolizing elite placement. Institutions and sectors are definitely ranked, but placement to high office in public as well as private spheres is in institutions have a lock on sponsorship of top offices, political or administrative. The third type is characterized by little status ranking. In Italy, there is virtually no non-university sector that could be second best, and all the universities can send graduates to elite positions in government and the professions. The system of the Federal Republic of Germany is somewhat more hierarchical than the Italian, since its non-university components devoted to technical and teacher training have a lesser standing than the universities. But there are few status differences among the universities, with no one or two places serving in the manner of Tokyo-Kyoto or Oxford-Cambridge, nor, as in the United States, are there universities competing for the status advantages of attracting the best students. These important national cases make it clear that institutional sectors tend not to remain merely that, but instead become segments of 
hierarchies that vary in steepness and rigidity.

\section{The Hierarchy Structure of Chinese Higher Education System}

With reference to the international educational standard classification, combining with the reality of Chinese higher education, the colleges and universities in China can be divided into three kinds of basic types in terms of academic university, applicable university with undergraduate courses, and vocational technological university or multiversity or mono-discipline university (Pan \& Dong, 2009). According to the classification based on different missions, Chinese higher education system can be divided into four levels: research-based universities, teaching-research-based universities, teaching-based colleges, and vocational-technical colleges (see Figure 1). In China, there are about 30-40 universities whose main mission is to do scientific research and cultivate high-level scientific manpower (postgraduate education); about 100 universities that pay the same attention to cultivating talents as to doing scientific research; about 500 teaching-based universities and colleges that focus on undergraduate education; and about 1,600 vocational technical colleges that mainly train technicians and workers.

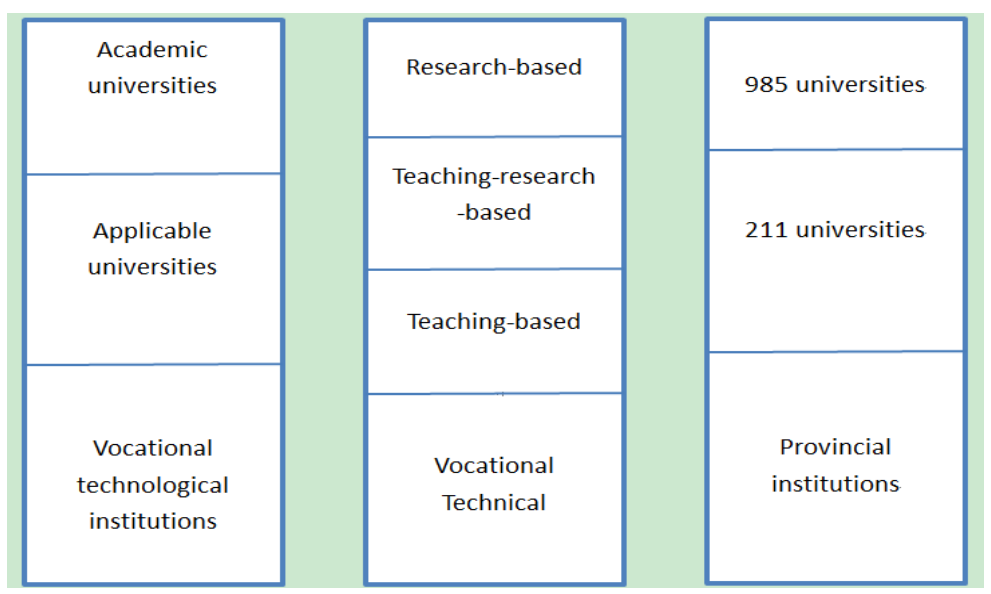

Figure 1. Different classification methods of higher education institutions.

According to classification based on organizational reputation, there is a steep hierarchy in Chinese higher education system (Han \& Zhang, 2014a). In Chinese higher education system, more than 40 universities are at the first level, whose goal is to be one of the international well-known and domestic first-class universities. These universities are directly governed by central authorities. These universities can obtain abundant funds annually provided by central ministries and commissions. Among them, Tsinghua University and Peking University are usually at the apex to become the world-class universities, funded by much more money from the central government. At the second level are about 100 universities whose goal is to build domestic high-level universities. These universities are mostly 211 project institutes and can obtain adequate funds allocated by central authorities. The provincial institutions are at the third level, including universities, vocational and technical colleges, and junior colleges. All the above-mentioned colleges and universities are almost public institutes, not private ones. In Chinese social environment, people usually prefer public key universities to private institutes. Only when they cannot succeed in entering public institutes, they have to choose the private institutes with high tuitions. It cannot be denied that only few distinctive private universities and colleges can gain as much reputation as public institutes. What is more, people usually prefer universities that educate liberal education to those vocational and technical colleges. The idea of "academic knowledge is more elegant than technology" is deep-rooted in Chinese mind. 
The classifications based on mission and on reputation are to some extent consistent but not perfectly corresponding. The research-based universities mostly obtain more reputation, while the vocational and technical colleges obtain less reputation. Exceptionally, only very few colleges that have distinguishing features and good employment situation can obtain higher reputation. The steep hierarchy of higher education system inevitably leads to the Matthew Effect. The institutes at higher level need not be anxious about funding, because they can obtain generous funds from the government and also produce revenues by their own advantages. However, those institutes at lower level usually fall into the dilemma of insufficient funds, which hinders their further development. In order to win higher reputation, the institutes at lower level are often inclined to imitate the mode of institutes at high level. For example, the vocational and technical colleges drift far from vocational and technical education in order to cater to the needs of liberal education. In order to enhance their status, the teaching-based institutes give up their duty of cultivating talents and spare no effort to do scientific research regardless of their conditions. The research-based universities would like to sacrifice time and resources that should be spent in doing research on continuing education and vocational education activities.

Colleges and universities cannot sustain the temptation of the market and stick to their own tasks, which leads to the chaos of tasks and hierarchy. Besides, the national assessment criteria of higher education system are uniform and rigid, which promotes the homogeneity of higher education institutes. Higher education institutes of different types and levels have to receive the uniform assessment criteria, which inevitably results in homogeneity. If some colleges and universities cannot cling stubbornly to their mission, they will just optionally meet the wants of outside, drifting aimlessly without a definitive direction or sense of progress.

\section{Conclusions}

\section{Conflict Between Hierarchical and Equipollent Structure of Higher Education}

The pros and cons of the division of sectors and the development of hierarchies are fundamental issues in public policy in higher education. The issues involve trade-offs among such values as equity, competence, and liberty. Minimizing sectors, and hence hierarchies, allows for more uniformity in practices and rewards. The single formal system composed of one type of institution gives greater strength to "coercive comparisons," in which "have-nots" exercise strong leverage for equity against the "haves," the less-noble against the noble (Kerr, 1978). If a country commitments to the equipollent allocation of resources among institutes and establish a uniform national degree that has the same value in the talent market regardless of its hierarchical status, the structure of higher education is not obviously hierarchical. In a more hierarchical higher education system, institutes at higher level not only undertake different mission, but also obtain and consolidate abundant resources by governmental policy and self-aggrandizement in order to attract the most excellent teachers and students, which in return consolidate and enhance their hierarchical status, so that forms a strict hierarchy of higher education system. Institutes at the lower level of hierarchy are faced with struggling developmental dilemma.

Modern higher education undertakes a mission that is to realize social justice- to make individual accept just treatment. Social justice means not only the equal access of higher education, but also unifying various criterions of higher education in order to make students in different institutes accept equal treatments and obtain the degree's diploma of identical value. Institutes at lower level aspire to obtain more resources to enhance their status. They exert strong influence in order to obtain the equal status and realize the equalization of higher 
education system. If the higher education system minimizes the hierarchy, higher education institutes will take on structural homogeneity and mission conflict. Along with the rolling up of higher education activities, more and more people aspire to get education. That easily results in structural deficiency, and cannot meet the needs. For example, too large-scale teaching and consult responsibilities undertaken by comprehensive universities occupy the time and resources that were assigned to scientific researches and talent training, which leads to the chaos of new and old functions of colleges and universities. The limited higher education institutes cannot meet more and more general and various activities needs.

Under the circumstances, the equipollent structure is not an appropriate choice. The pursuit of equipollent reputation is as illusory as the pursuit of classless society - there is no distinction among different institutes. The higher education system with multiple structure helps to undertake heavy tasks and reduce the conflict between contradictory activities of higher education. The activities, such as service society, may be carried out in some separate institutes, for example, the community colleges established in the United States, the engineering colleges in French, the open universities in England, and the local technical colleges. Higher education institutes of different levels and types respectively accomplish different objectives and tasks, which form the ordered structure of higher education system. However, when the hierarchy of higher education system forms, there will be some inequality in assessment and reward criterion. The extreme hierarchical structure will lead to serious social problems. For example, the phenomenon that University of Tokyo and Kyoto University in Japan monopolize senior posts results in serious nepotism. Even though the institutes educate a few high-quality talents for governmental departments and industrial sectors, it forms a closed loop that impedes to educate more talents and to produce more high-quality research results.

\section{Reflections on Chinese Higher Education System Structure}

In view of the rigid hierarchical structure of higher education in China, some measures should be taken in order to manage the conflict. Higher education institutes should locate reasonably to enhance their reputation in the respective levels. The government needs to be on the alert on the hierarchical structure of higher education system and maintaining the mobility of hierarchical levels.

Higher education institutes should locate reasonably to enhance their reputation at their respective levels. Nowadays, the demands of social development are diversified and multilevel. There should be enough institutes of all levels and status in higher education system to meet various social needs. The hierarchy does not mean lowliness or nobleness of institutes but separation of tasks. Any institutes of different types and levels can cultivate top-notch and first-rate talents and turn into a famous university that is well-known domestically and influencing internationally. There is no need for colleges and universities to pursuit comprehensive and mutual rivalry and imitation. It is enlightening that there are the most diversified institutes of American higher education in the world. The institutes at different levels should locate reasonably their special tasks and goals, develop their strong points and avoid their weaknesses, and try to enhance their social reputation in the respective levels. The research-based universities should concentrate on scientific research and cultivate research talents; the teaching-based institutes should devote to cultivating high-quality undergraduates; and the vocational and technical colleges should endeavor to train special technical personnel who have strong operational capability. Colleges and universities should exploit their strengths, prioritize some disciplines or majors, shape their own unique characteristics, enhance students' quality, and guarantee graduates a good future, which are the important approaches for institutes to obtain higher reputation. 
Higher education institutes should be self-disciplined in order to promote their sound development at separate levels. There is some chaos of location in hierarchical structure of Chinese higher education system, which is against the diversified development of higher education institutes. If the poor institutes are at the same hierarchy level with rich institutes, the former will insist being treated equally as the later; if the poor institutes are at a separate level, then their demand will not too strong. Colleges and universities at different hierarchical level should consciously stick to their own mission and engage in separate task, which helps to maintain the order of academic system. That is to say, the vocational and technical colleges are a kind of institute which engages in training technicians, not in scientific research or knowledge innovation. The teaching-based institutes should concentrate on the task of cultivating undergraduate talents. The research-based universities should devote to elite education and scientific research, not vocational or technical education. So, institutes at different hierarchical level should be self-disciplined to avoid offside and distortion of tasks, which will maintain the order of higher education and promote their sound development at separate levels.

The government needs to be on the alert on the hierarchical structure of higher education and maintaining the mobility of hierarchical levels. During the early times, the compelling institutional changes oriented by the government influence the hierarchal structure of higher education (Zhang, 2009). Now, the concept of equal division is so popular that public funds should be increased or reduced as equally as possible among different departments. Because the diversified requirements of society call for different types of institutes, the government should pay close attention to every hierarchical level of higher education system and treat these institutes equally. Meanwhile, higher education institutes should maintain the mobility of different hierarchical levels to avoid the inbreeding of scientific researchers and the perfect monopoly on senior posts in governmental and enterprise departments. Then, the potential excellent talents can be selected from the lower hierarchical levels of higher education and effectively prevent the inertia of the actual higher talents, not as the Japanese example that the entry into university just means senior posts.

\section{References}

Clark, B. (1983). The higher education system-Academic organization in cross-national perspective (pp. 67-72). Berkeley, Los Angeles: University of California Press.

Han, M., \& Song, W. (2014). Xin zhong guo cheng li yi lai gao deng jiao yu qu yu jie gou de zhi du an pai yu fansi (The system arrangement of higher education's regional structure since the establishment of the People's Republic of China and its reflections). Journal of Henan University (Social Science), 1, 125-141.

Han, M., \& Zhang, D. (2014a). Structural changes in Chinese higher education system: Public and private HE mix. International Journal of Comparative Education and Development, 16(2), 212-221.

Han, M., \& Zhang, D. (2014b). Private higher education in China and the US: From a comparative perspective. Journal of US-China Education Review B, 24(4), 126-135.

Kerr, C. (1978). Higher education: Paradise lost? Higher Education, 7, 261-278.

Kim, S., \& Lee, J. (2006). Changing facets of Korean higher education: Market competition and the role of the state. Higher Education, 52(3), 557-587.

Pan, M., \& Dong, L. (2009). Research on the classification, orientation and characteristic development of colleges and universities. Educational Research, 2, 33-38.

Teichler, U. (2006). Changing structures of the higher education systems: The increasing complexity of underlying forces. Higher Education Policy, 19(4), 447-461.

Zhang, D. (2009). The institutional analysis of structural development and change: Higher education in China from 1998 to 2007. China Higher Education, 12, 1-7. 